\title{
The development trend of mobile Internet and its impact on the global economy
}

\author{
Xinzhou HE \\ Changjiang Professional College \\ Wuhan, 430074 China
}

\begin{abstract}
In recent years, the number of mobile Internet users increases rapidly, mobile Internet users scale gradually surpass the fixed scale, the scale of the domestic Internet is growing day by day, mobile Internet has become the focus of the current competition in the global information industry. The development of mobile Internet business has brought endless space for mobile network application, has promoted the indepth development of broadband mobile network. The paper first briefly introduces the definition, characteristics and the development of mobile Internet, then the development trend of mobile Internet today under the circumstances is studied, including users' demands trends for the mobile Internet, the producer of the emerging generation of mobile Internet applications, and finally it summarizes and gives the prospect of the development trend of mobile Internet from a variety of perspective, therefore, based on the analysis of current situation 、 characteristics and trend of the development of Chinese Internet development, this paper constructs the economic growth model, selects the appropriate variables and data, studies the economic contribution of the development of the Internet in size, and explores the characteristics of Internet promotion effect on the economy, and makes recommendations for the development of the Internet.
\end{abstract}

Keywords- mobile Internet; operators; economic development

\section{INTRODUCTION}

With the further continuous innovation of Web application technology and the further development of broadband wireless mobile communication technology, the development of mobile Internet services will become another impetus following the development of the Internet broadband technology, making the Internet more popular, and with its portability, authentication, identification and other unique advantages, it provides new space for development and a new commercial mode of the sustainable development for traditional Internet services. From the initial business in the form of simple text browser, ringtone downloads and other forms of business to the current depth of integration with the Internet business, mobile Internet services is growing as the strategic focus of the mobile operator business development. Definition of mobile Internet: mobile Internet is the emerging markets of Internet and mobile communication integrated after developing individually, currently showing the trend that the mobile Internet product is stronger than the Internet mobile product. From the definition of the technical level, with broadband IP as core technology, it can provide simultaneous voice, data and multimedia services open basic telecommunications network; from the definition of terminal, users use mobile phones, net books, laptops, tablets, smart phones and other mobile terminal, access the mobile communication network services and Internet services over the mobile network. The core of the mobile Internet is the Internet, therefore it is generally believed that the mobile Internet is the supplement and extension of desktop Internet and applications and content of the mobile Internet is still fundamental.

\section{STUDY THE FUTURE DEVELOPMENT TREND OF MOBILE INTERNET}

\section{A. Competition in the field of mobile Internet}

Mobile Internet is a comprehensive value chain competition. Mobile Internet industry chain constant fission and refinement, diversification, each subject in the value chain extends laterally continuous, so the operators' competition in the field of mobile Internet business is not only from homogeneous enterprises, but also from heterogeneous enterprises such as Tencent IM, microchannel, Apple points to the operator for communications. "Terminal + service" model has become the industrial chain of high value in return areas, pulling up the smile curve, also has forces leading to the development of related industries and the impact of mobile Internet competition operations. The mode of value chain operator equipment manufacturers as the core is faced with challenge.

\section{B. Four power of mobile Internet development}

Terminal manufacturers, system platforms, Internet applications and mobile operators are four major power of the Internet development. This is the power of a few large chain, closely.

Terminal: Around the terminal, it builds integrated mobile Internet service ability. It develops intelligent, builds application store, and holds Internet service entrance, while participating in the application operations, obtaining the long-term profit. Terminal manufacturers should be integrated industry chain capability, featured strong operating system partners, operators and other partners. Platform: Platform is the interface between the mobile terminal and key applications is the commanding heights of the mobile Internet strategy. It combines the ability of industry chain, and combines the operating system and terminal system closely. It builds application store, hold Internet service entrance. It is also involved in the application operations, obtaining the long-term profit. 
Internet applications: It makes the best desktop Internet products and services mobile. Desktop Internet products are gradually transferred to the mobile Internet. Internet applications should make full use of operators' network resources and capabilities to penetrate the field of operators or customized terminal. Operators: Operators Integrates chain and resource, and it will be the best Internet services introduced to the phone. It created an ecological environment. Operators can also provide products and services directly, using the acquisitions, mergers, investment and other ways, select popular Internet companies, in order to enhance the ability of Internet service.

\section{THE INTRODUCTION OF INTERNET AND ECONOMIC GROWTH}

Internet started early in the developed world, has developed more than forty years, so compared to domestic, foreign research for Internet and economic growth is more systematic and comprehensive, they infiltrate the effects of the facilities such as the Internet on GDP, trade and other aspects from the Internet, broadband investment, telecommunications infrastructure and other aspects, having high research value.

Compared to other countries, Chinese Internet development started late, so naturally related research is lagging behind, especially the study of the relationship between economic growth and the Internet itself, it is only a handful. Throughout the literature, what can be used for reference is correlation analysis of Internet, broadband, telecommunications infrastructure and information elements and the economy. The influence of Internet penetration rate and the Internet infrastructure construction level of economic development are significant. Provincial sectional data shows that in 2006, the Internet penetration rate of economic growth in the provinces of elasticity is 0.17 , while the number of ports of broadband on economic growth elasticity is 0.09 , the role of the Internet has not to be ignored.

Study of the factors of TFP growth

Development of the Internet is one of the engines of economic growth, while economic growth is the result of joint action by much factor, the analysis of economic growth is naturally to consider the impact of various factors. With the changing economic environment and in-depth knowledge of the economy, the related research on economic growth in China has experienced a neoclassical growth theory, new growth theory based on, and then to the total factor productivity (TFP) of the process - in particular, in recent years, many studies have adopted ways TFP growth analysis. Enhance TFP mainly rely two ways, the first is microscopic technological advances, which mainly relies on strengthening $\mathrm{R} \& \mathrm{D}$ investment and the introduction of high-end technology, so that the production efficiency is improved; the second is to rely on a variety of ways to improve the efficiency of resource allocation. Throughout the many economic growth theory and literature, physical capital, labor and technological progress are the recognized driving force of economic growth, at the same time, for the other factors are also emerging contributions to the economic growth.

\section{ANALYSIS OF INTERNET DEVELOPMENT AND ECONOMIC GROWTH}

After Chinese Internet experienced research experimental stage and the initial stage, since 1997, four open civilian access backbone network interconnection, its speed of development attracts worldwide attention. Only counting the number of Internet users, only 62 million Internet users in 1997, to the end of 2013, the number of Internet users reached 618 million, coverage rate was $45.8 \%$, the total number was the world's first. Compared with the period of the growth rate of GDP can be seen in the late 90's, up to now, China GDP growth rate has been maintained at a high level. Throughout these years of Internet development path, from the beginning of people's eyes, "new things" to now an indispensable element in people's daily lives ,Internet is involved to people's daily life strongly, also has a profound affected on the national economy. This chapter will analyze the mechanism of the Internet to promote economic development on the basis of discussing the meaning of the development of Internet.

\section{THE PROSPECT OF MOBILE INTERNET}

\section{A. Operating system is a competitive high ground}

The main platform industry standard from diversification to the relative normalization is general rule of industrial development, PC, mobile communications, digital television and other areas are to be so. To the mobile Internet, the leading platform for decision camp attribution is terminal operating system. In the mobile Internet business model innovation, the application store tightly coupled with the operating system, the operating system determines the application development SDK; in the innovation of industrial ecology mode, the bearing platform operating system is not only the business application resources, but also the platform of hardware resources. So the current intelligent terminal operating system has become parties to giant integration of the industry grasper and strategic focus, and constantly to the fields of Pan terminal extension, tablets, smart TVs, automotive systems are in the application of intelligent terminal operating system. In the context of the Internet and the terminal has become the main platform for business innovation, the terminal operating system determines the service entry, business development standards, developers camp and hardware adapter that can directly affect the network and information security, prompt information from the center for the PC evolved into the mobile phone as the center, it is the strategic high ground in the new period of international competition in the technology industry, and its significance is even beyond the era of desktop PC operating system.

\section{B. Mobile Web operating environment to replace the operating system}

Traditional Web technology enables Internet content to access platform across the terminal, an application platform change. In the long term, with HTML5 technologies and cloud computing technology continues are developing 
mature, high efficiency mobile Web operating environment, cross-platform future is likely to replace the operating system to become the new high ground mobile Internet competition, the business model will be a new round of major changes after the mobile dream network, the application store. Apple App Store as the representative of a closed model may be broken, a large number of high-quality Web applications will run Web-based environment bypass the app store, online or locally to provide services to users, the importance of applications store decreases. In this trend, global technology giants have begun to actively lie out, expand the business model for a new round of exploration. Microsoft patches installed technology is defined vulnerabilities: vulnerabilities are weaknesses that can be used during the attack. The weaknesses include software, hardware, functional design, improper configuration or program shortcomings. A study reported that there is the prevalence of loopholes and flaws in the software. Internet users often use the network in the process of being attacked because of network vulnerabilities, system program is focused on the vulnerabilities of viruses and hackers point, so be prompt to download patches and upgrades to prevent malefactors exploit to threaten our network and information security.

Internet applications has covered the aspects of people's work, live, entertainment, Internet business development model can be summarized as follows: expand the user scale, optimize the user's experience, improve customer's stickiness. Desktop Internet era is mainly connected to the Internet through a Web site; mobile Internet era, in order to apply to access the Internet will become increasingly popular; only understand this trend, can we build a successful business model.

\section{Construction of the Team Safety Management}

There is no absolute security information network security technology to strengthen the construction and management of safety standardization, to develop a sound safety management system is to achieve an important guarantee for the security of network information in a computer network system. Network administrators and network users should work together to take all effective ways to maintain network security, crack down on acts of sabotage, to minimize the threat of computer networks, in addition, we should strengthen the security of computer information and standardized management, improve security management technology to enhance awareness of security managers and users of the network, because the IP address is often overlooked management, in order to maintain network security, IP address resource management should be unified, because of the theft of IP resources should be disciplined. To prevent unauthorized access to data being occurring, the network administrator can set passwords and application data operations.

Business model represented in AppStore will continue to lead the mobile Internet era, so that production of global products will be possible, rather than doing a local product. This global competition forces to produce the best products, and users can conveniently experience the world's best products. In the next 3 to 5 years, through investment, joint ventures, etc., there will be more "international" mobile Internet companies. Globalization and internationalization at the same time, in different countries at different stages of development, users have different needs, so the service must be localized (including personnel localization).

\section{CONCLUSIONS}

When using the improved Cobb-Douglas model to estimates the contribution of each factor to economic growth, in dealing with the indicators established production function model, as well as elements of the contribution of the calculation method and other issues need to be further explored. Development of the Internet itself is a complex and multifaceted problem, but also a dynamic problem, as time and technology developed, it will have more updated content. This selection of indicator data users, websites and $\mathrm{CN}$ domain names of these three areas to measure the level of development of the Internet, there should be several other factors not taken into account in this article, this aspect should be improved. Due to the limitations of individual academic and perspective research, the study of some problems is still not enough deep and comprehensive, pending further study.

\section{References}

[1] Zeng Jian. Having built mobile Internet industry chain cooperative and competitive research [D].Beijing University of Posts and Telecommunications, 2009.

[2] Yang Xiaofang. The new business model is based on the development of mobile Internet research [D].Beijing University of Posts and Telecommunications, 2013.

[3] Wu Ajing. Mobile Internet companies in patent litigation strategy empirical research [D]. Xiangtan University,2013.

[4] Cheng Ziyang. The development trend of mobile Internet services [J] Mobile Communications, 2012.05: 30-35.

[5] Shu Tianhong. Mobile Internet trends and business model [J] Science and Technology Communication, 2012.2: $190+176$.

[6] Chen Ying. Regional Differences of Chinese Internet development[D]. Southwestern University, 2012.

[7] Yu Xiaohui. Mobile Internet development and thinking [J] telecommunications network technology, 2008.12: 21-27.

[8] Yu Zhicheng. Development status and development trend of mobile Internet [J] Mobile Communications, 2008.09: 22-24. 